\title{
Refractory Hypercalcemia in a Jamaican Woman
}

Amaris Balitsky MSc, MD, Jonathan So, PhD, MD, Caroline Chessex, MSc, MD

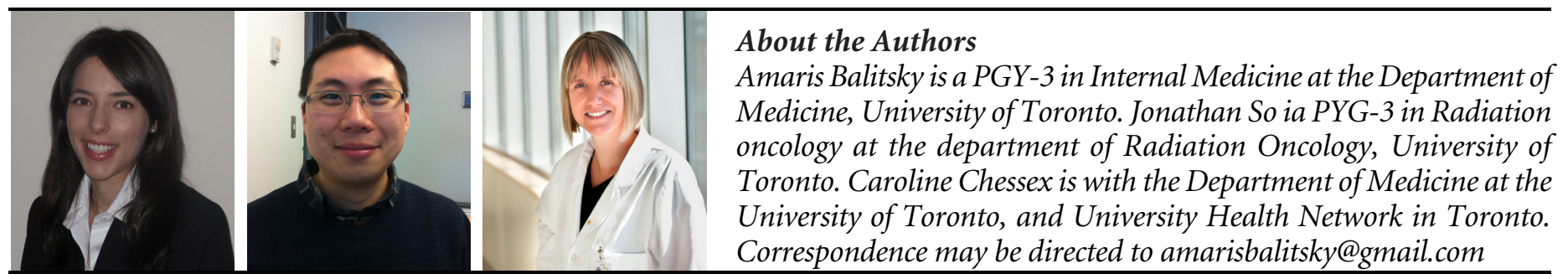

\begin{abstract}
Summary
The two common differential diagnoses for hypercalcemia are malignancy and hyperparathyroidism. In this case of a young woman with hypercalcemia refractory to bisphosphonate treatment, Vitamin D and parathyroid hormone releasing peptide (PTHrP) levels were normal. She was found to be positive for HTLV-1 and later diagnosed with Adult T-cell leukaemia/ lymphoma, with CNS involvement. After treatment with R-CHOP therapy with intrathecal methotrexate, her symptoms improved and her calcium returned to normal. The differential diagnosis and treatment of hypercalcemia is further discussed.
\end{abstract}

\section{Summaire}

Les deux diagnostics différentiels courants en matière d'hypercalcémie sont la malignité et l'hyperparathyroïdie. Dans le cas discuté, une jeune femme dont l'hypercalcémie est réfractaire aux diphosphonates présente des taux normaux de vitamine $\mathrm{D}$ et de protéine liée à l'hormone parathyroïde (PTH-rP). Elle se révèle être positive au HTLV-1 et l'on établit par la suite un diagnostic de leucémie à lymphocytes $\mathrm{T}$ de l'adulte avec atteintes au SNC. Après un traitement CHOP-R à l'aide de méthotrexate intrathécal, les symptômes se sont améliorés et la calcémie est revenue à la normale. Les diagnostics différentiels et le traitement de l'hypercalcémie sont analysés plus en détail.

\section{Case}

Mrs. M is a 37-year-old, Jamaican-born woman, who presented to hospital with headache, nausea and vomiting, polydypsia and polyuria. She was subsequently found to have a calcium level of $4.71 \mathrm{mmol} / \mathrm{L}$ and undetectable levels of PTH. She was admitted for hypercalcemia management and work-up.

Her past medical history was significant for uterine fibroids, with a planned hysterectomy. She had previous abnormal Pap smears, with subsequent normal results. Her past surgical history was significant for tubal ligation. She did not take any medications and had no known drug allergies.

She did not have any known family history of malignancy or autoimmune disorders. Her social history was not significant for smoking, alcohol or recreational drug use.
Mrs. $M$ was treated with intravenous Pamidronate and intravenous fluids. Vitamin D and parathyroid hormonerelated peptide (PTHrP) levels were normal. Serum protein electrophoresis (SPEP) was negative. A CT of the thorax revealed 2 small breast nodules. A CT of the abdomen revealed an enlarged uterus with multiple fibroids, the largest fibroid measuring $8.7 \times 7.1 \mathrm{~cm}$. In addition, there were prominent retroperitoneal lymph nodes (largest $1.2 \mathrm{~cm}$, paraaortic) and evidence of mesenteric paniculitis. She was discharged with an improved calcium level of $2.62 \mathrm{mmol} / \mathrm{L}$ and a working diagnosis of paraneoplastic syndrome secondary to a possible uterine sarcoma. An outpatient gynaecology follow-up was scheduled. 
Two days later, Mrs. M presented to the emergency department with recurrent symptoms and an elevated calcium of $4.5 \mathrm{mmol} / \mathrm{L}$. She was given intravenous Zoledronic Acid and Pamidronate. As part of a paraneoplastic work-up, she underwent a core biopsy of the breast, which was negative for malignancy and revealed a fibroadenoma. An endometrial biopsy was also negative for malignancy.

In the meantime, a human T-lymphotropic virus (HTLV) serum blood test had come back positive from her previous admission. On that same day, Mrs. M became confused with concurrent hypoxia. Imaging revealed a right pleural effusion. She was admitted to the ICU for high flow oxygen and chest tube drainage of $800 \mathrm{~mL}$ of pleural fluid. Given her HTLV status and refractory hypercalcemia, a search for lymphoma was undertaken. Cerebrospinal fluid from a lumbar puncture and fluid from a paracentesis were positive for adult T-cell lymphoma (Figures 1 and 2). A CT-guided fine-needle aspiration of the paraaortic lymph node also revealed adult T-cell lymphoma. The lymphoma service was consulted and they commenced R-CHOP therapy with intrathecal methotrexate for stage four, HTLV-associated adult T-cell lymphoma. In addition to other prophylactic medications, she was given prophylactic doses of Ivermectin for possible Strongyloides stercoralis co-infection.

\section{Discussion}

Adult T-cell leukaemia/lymphoma

Adult T-cell leukaemia/lymphoma (ATLL) is an uncommon

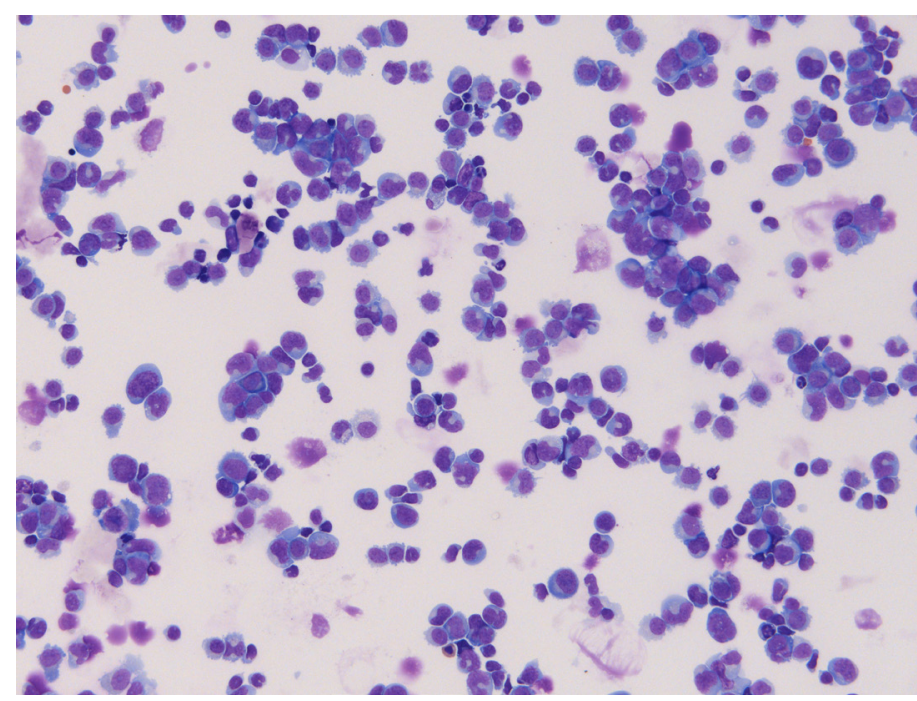

Figure 1. May Grunwald Giemsa stained CSF preparation, low power (20x objective) CSF sample from our patient with HTLV-1 associated adult T-cell lymphoma. peripheral T-cell neoplasm associated with HTLV-1. The World Health Organization recognizes ATLL as a distinct entity. There are 4 clinical variants of ATLL: acute, lymphomatous, chronic, and smouldering (Table 1). ${ }^{1}$ The acute presentation, as seen in our patient, is the most common presentation, accounting for $65 \%$ of ATLL cases and associated with a worse prognosis. ${ }^{1}$ Hypercalcemia is seen in $70 \%$ of the acute variant of ATLL. ${ }^{2}$

ATLL was first described in Japan and often seen in the Caribbean, Central Africa and Southeastern United States populations. About 20 million individuals worldwide are carriers of HTLV-1 with varying prevalence depending on geographic area. The virus has a long latency period (20-40 years) with a lifetime progression to ATLL of $2.1 \%$ for women and $6.6 \%$ for men.

Patients with HTLV-1 induced malignancies are immunocompromised and at risk of developing opportunistic infections. Infections with bacterial, fungal, protozoal and viral are often found at the time of diagnosis. Infections with Strongyloides stercoralis can be severe and fatal. ${ }^{3}$ There is a thought that infection with this parasite plays a role in the development of ATLL in healthy individuals with positive serology. For this reason, our patient was empirically treated with ivermectin.

In individuals with ATLL, the peripheral blood film is characteristic for flower cells, which are medium sized lymphocytes with condensed chromatin and convoluted nuclei, resembling a flower. ${ }^{4}$ Bone marrow may show infiltration by lymphocytes that appear similar to those seen

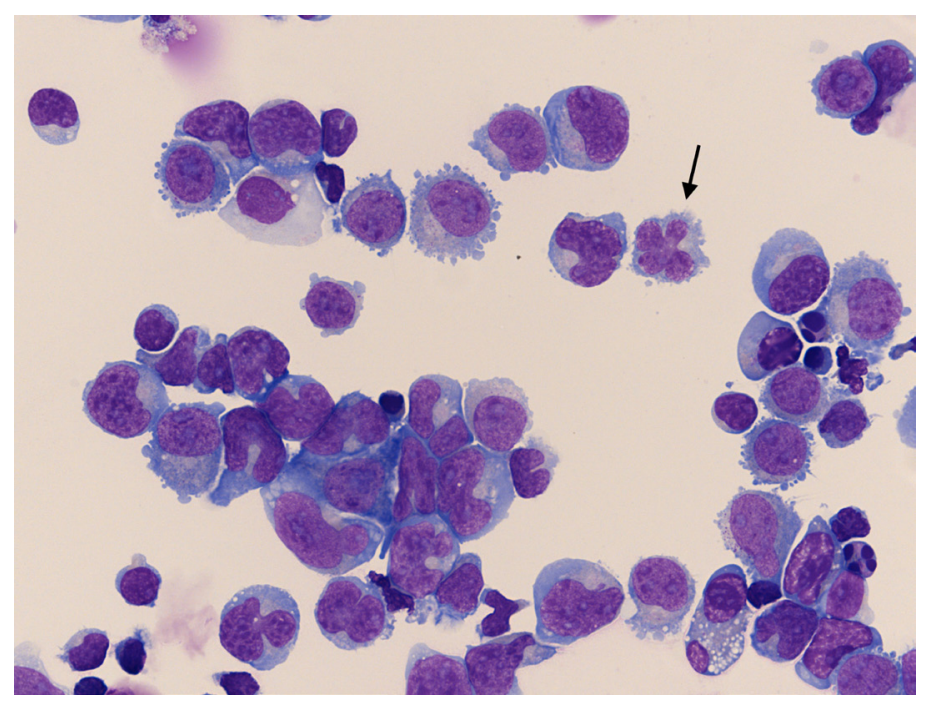

Figure 2. May Grunwald Giemsa stained CSF preparation, high power (63X objective) showing abnormal lymphoid cells with deeply indented or convoluted nuclei. Some (arrow) resemble floret cells, which are more typically identified in peripheral blood films. 


\begin{tabular}{|c|c|}
\hline \multicolumn{2}{|c|}{$\begin{array}{l}\text { Clinical forms of adult T-cell } \\
\text { leukemia/lymphoma (ATLL) }\end{array}$} \\
\hline Variant & Clinical presentation \\
\hline Acute & $\begin{array}{l}\text { - leukemic picture } \\
\text { - high LDH, hypercalcemia }\end{array}$ \\
\hline Chronic & $\begin{array}{l}\text { - lymphocytosis }>4 \times 10^{9} / \mathrm{L} \\
\text { - lung, liver, or node involvement } \\
\text { - normal calcium } \\
\text { - normal LDH }\end{array}$ \\
\hline Smouldering & $\begin{array}{l}\text { - skin and/or lung infiltrates } \\
\text { - no other organ involvement } \\
\text { - normal lymphocyte count } \\
\text { (1-5\% ATLL cells) } \\
\text { - normal calcium } \\
\text { - normal LDH }\end{array}$ \\
\hline Lymphoma & $\begin{array}{l}\text { - organomegaly } \\
\text { - less than } 1 \% \text { circulating leukaemia cells } \\
\text { - high LDH } \\
\text { - possible hypercalcemia }\end{array}$ \\
\hline
\end{tabular}

Table 1. Clinical forms of Adult T-cell leukemia/lymphoma (ATLL). LDH, lactate dehydrogenase.

in the peripheral blood. ${ }^{4}$ Lymph node histology will not help distinguish from other forms of T-cell lymphomas. ${ }^{4}$ Characteristic immunophenotypic profile of ATLL consists of CD3+, CD4+, CD7-, CD8-, CD25- (which recognizes the interleukin-2 receptor). Cases associated with $\mathrm{CD} 4+$ and CD8+ have a worse clinical course.

The prognosis for the acute and lymphoma variant of ATLL is poor. In a Japanese study which evaluated outcomes in 818 Japanese patients with ATLL, ${ }^{5}$ the authors found that median survival was 6 months and only $5 \%$ of those with acute type have a 4-year survival. In a review of new therapeutic approaches for ATLL, those with lymphoma respond better to conventional aggressive chemotherapy regimens, and slower to zidovudine and interferon, antiviral therapies. ${ }^{6}$ Postinduction chemotherapy is followed by maintenance therapy with zidovudine and interferon. Treatment for ATLL is still controversial as there are no randomized trials, given its low cure rate.

\section{Hypercalcemia}

Our patient presented with hypercalcemia presumed to be secondary to a paraneoplastic process. Between 5-30\% of patients with cancer will develop hypercalcemia over the course of their illness. ${ }^{7}$ Cancer is the second leading cause of hypercalcemia, after primary hyperparathyroidism, in ambulatory settings; however, cancer is the leading cause of hypercalcemia in hospitalized patients. ${ }^{8}$ Multiple myeloma, lung, breast, ovarian and renal cancers account for most cases of cancer-induced hypercalcemia $(\mathrm{CIH}) .{ }^{12}$ The 3 main mechanisms in which these cancers cause hypercalcemia are the production of a parathyroid hormone-related protein (PTHrP), creation of lytic bone lesions with concomitant release of cytokines (tumour necrosis factor and interleukin-1), and release of calcitriol, the active metabolite of vitamin D. In ATLL, the mechanism seems to be a combination of PTHrP production and a unique over-expression of receptor activator of nuclear factor kappaB (RANK) ligand on the leukaemic cell surface leading to osteoclast activation. ${ }^{11}$ Unfortunately, aside from multiple myeloma and breast cancer, in $\mathrm{CIH}$, hypercalcemia is a marker of poor prognosis signifying a mean survival of 2-3 months. ${ }^{9}$ Therefore, in a patient who initially presents with hypercalcemia, it is important to rule out malignancy.

The most useful test to rule-in CIH is a PTH level (Figure 3). A supressed PTH differentiates CIH from other causes of hypercalcemia (e.g. primary hyper-parathyroidism or familial hypocalciuric hypercalcemia). Less than $5 \%$ of patients will have $\mathrm{CIH}$ from ectopic production of $\mathrm{PTH}$ (mostly parathyroid cancers). ${ }^{10}$ Further investigations can narrow the search for a malignancy. Bone lesions from metastatic or infiltrative cancers may lead to elevated alkaline phosphatase, and can be found on X-ray or CT imaging. A monoclonal gammopathy found on SPEP is specific for multiple myeloma. Outside the bone, humoral hypercalcemia of malignancy can be found by assaying for the specific hormones. PTHrP is produced by some adeno and squamous cancers, and does not cross-react with PTH assays. Calcitriol is produced by some hematologic malignancies, such as ATLL.

Treatment of hypercalcemia is focused on the excretion of calcium and the inhibition of bone resorption. The mainstay of acute management is the treatment of dehydration and volume expansion through IV hydration, which inhibits proximal tubular reabsorption of calcium and leads to calciuresis. Once sufficiently euvolemic, loop diuretics (e.g. Furosemide) may be used to further promote the excretion of calcium. ${ }^{9}$ However, volume expansion and diuretics only achieve temporary control of hypercalcemia in the acute setting. ${ }^{8}$ What is needed is the inhibition of osteoclasts and bone resorption through bisphosphonates, such as Pamidronate and Zoledronic acid. Their maximal effect is reached within 2-4 days with a median duration of effect of approximately 30 days..$^{12}$ For refractory hypercalcemia, the monoclonal antibody Denosumab has seen some success for lytic lesions of breast cancer or multiple 


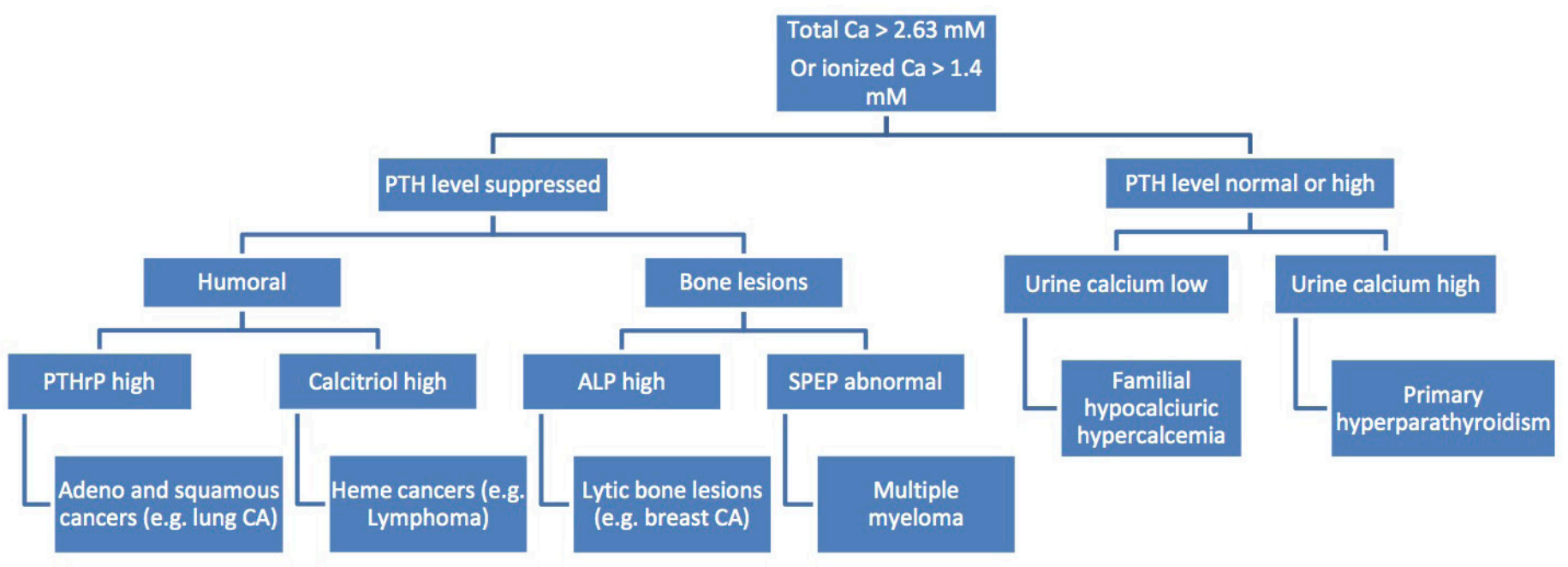

Figure 3. An approach to hypercalcemia. Ca, calcium; PTH, parathyroid hormone; PTHrP, parathyroid hormone related peptide; ALP, alkaline phosphatase; SPEP, serum protein electrophoresis; CA, cancer.

myeloma. ${ }^{9}$ It binds RANK ligand and inhibits osteoclast maturation. Fortunately, resolution of hypercalcemia due to ATLL usually accompanies treatment of the lymphoma itself, signifying decreased tumour burden. Newer, more experimental therapies are being developed that specifically target mechanisms of hypercalcemia, such as PTHrP. A recent study showed the promise of a humanized monoclonal antibody against PTHrP in animal models of $\mathrm{CIH} .{ }^{9}$

\section{Conclusion}

This is a case of a young woman with hypercalcemia refractory to bisphosphonate treatment. She was found to be positive for HTLV-1 and later diagnosed with Adult T-cell leukaemia/ lymphoma, with CNS involvement. After treatment with $\mathrm{R}-\mathrm{CHOP}$ therapy and intrathecal methotrexate, her symptoms improved and her calcium returned to normal. It is important to consider malignancy in cases of hypercalcemia.

\section{Acknowledgements:}

Many thanks to Dr. William Geddie, hematopathologist at the University Health Network (Toronto), for the micrographs from the case and critical input to the manuscript.

\section{References:}

1. Shimomaya M. Diagnostic criteria and clinical subtypes of ATLL. A report from the Lymphoma Study Group (1984-87). Br J Haematol. 1991;79:428-37.

2. Qayyum, S. \& Chol, JK. Adult T-cell leukemia/lymphoma. Arch Pathol Lab Med. 2014 Feb;138(2):282-6.

3. Yamaguchi K, Matutes E, Catovsky D, et al. Strongyloides stercoralis as candidate cofactor for HTLV-I induced malignancies. Lancet 1987;ii:94-5.

4. Matutes, E. Adult T-cell leukaemia/lymphoma. J Clin Pathol. 2007;60:13731377

5. Shimoyama M. Treatment of patients with adult T-cell leukemia-lymphoma: an over- view. In: Advances in Adult T Cell Leukemia and HTLV-1 Research (Takatsuki K, Hinuma Y, Yoshida M, eds.). Tokyo: Japan Scientific Societies Press, 1992;39:43-56.

6. Bazarbachi A, Ghez D, Lepelletier Y, et al. New therapeutic approaches for adult T- cell leukaemia. Lancet Oncol. 2004;5:664-72.

7. Grill V and Martin TJ: Hypercalcemia of malignancy. Rev Endocr Metab Disord. 2000; 1: 245-263.

8. Walls J, Ratcliffe WA, Howell A, et al. Parathyroid hormone and parathyroid hormone- related protein in the investigation of hypercalcemia in two hospital populations. Clin Endocrinol (Oxf). 1994;41:407-13.

9. Lumachi F, Brunello A, Roma A, et al. Cancer-induced hypercalcemia. Anticancer Research. 2009;29:1551-1556.

10. Kunnathuparambil SG, Payangappadom PK, Yerol PK, et al. Hypercalcemic crisis due to adult $\mathrm{T}$ cell leukemia: a rare cause of paralytic ileus. Annals of Gastroenterolo- gy. 2012;25

11. Nosaka K1, Miyamoto T, Sakai T, et al. Mechanism of hypercalcemia in adult T-cell leukemia: over-expression of receptor activator of nuclear factor kappaB ligand on adult T-cell leukemia cells. Blood. 2002 Jan 15; 99:634-40.

12. Jibrin IM, Lawrence GD, Miller CB. Hypercalcemia of malignancy in hospitalized patients. Hospital Physician. 2006 Nov; 29-35.

13. Carrol MF, Schade DS. A practical approach to hypercalcemia. Am Fam Physician. 2003 May 1;67(9):1959-1966. 